\title{
De la zarzuela a la ciencia ficción: El anacronópete, de Enrique Gaspar. Expansión de los límites de lo fantástico en la coyuntura del nacionalismo
}

\author{
From Zarzuela to Science Fiction: \\ Enrique Gaspar's El anacronópete. \\ An Expansion of the Limits \\ of the Fantastic through Conjunction with Nationalism
}

\author{
Maximiliano Brina \\ Universidad de Buenos Aires \\ maximilianobrina@gmail.com
}

\begin{abstract}
This article addresses Enrique Gaspar's novel El anacronópete (1887) by means of the articulation of the fantastic genre and nationalism. The nineteenth century witnessed a powerful scientific and technological development, which introduced economic, political and social changes. This can be traced in literature, especially in the second half of the century: for example, in the antagonistic positions between Emilio Ferrari and Gaspar Núñez de Arce in the field of poetry, or novels by Benito Pérez Galdós as Doña Perfecta (1876), in which the tension between the countryside and the city is compared to that existing between tradition and modernity. In this context, the value of Gaspar's novel surpasses the anecdote of presenting the first time machine in literature, eight years before Wells's. Its value lies in the way in which, starting from the articulation of scientific and literary discourse, it expands the limits of the fantastic while using the procedure to address the question of national identity. The action takes place during the International Exhibition in Paris in 1878. The novel shows the popularity of the "famous Jules Verne" in Spain, whose "marvelous hypotheses" will be considered "children's toys in the face of the magnitude of the real invention of the modest Zaragoza neighbour of Spain". More than a science fiction novel, the text calls for the incorporation of concepts related to the process of creation of national identities from such disciplines as history and sociology.
\end{abstract}

Keywords: 19th century Spanish literature, the fantastic, science fiction, nationalism 
Mi propuesta es presentar la interacción entre el discurso científico y el literario en la España decimonónica con el objeto de dar cuenta de la forma en que dicha interacción estuvo atravesada por el proceso de sintetización de una identidad nacional, con particular interés en los textos que abordan los viajes interplanetarios y temporales. Podríamos proponer la oda "A la invención de la imprenta" que el madrileño Manuel José Quintana (1772-1857) compuso en 1800 -y que Friedrich Engels traduciría al alemán cuarenta años después en ocasión de los festejos por los cuatrocientos años del invento de Gutemberg- como un texto inaugural en lo concerniente a la interacción entre el vertiginoso desarrollo de la ciencia y la tecnología, por un lado, y la producción literaria en el siglo XIX por el otro, época de un potente desarrollo científico y tecnológico acompañado de profundos cambios económicos y sociales. La literatura no fue ajena a estos cambios y se nutrió de ellos, cosa que se verifica no solo en forma referencial -a través de la presencia de nuevas palabras, ambientes y personajes- sino también en la aparición de nuevas formas de narrar $\mathrm{y}$, gracias al crecimiento del periodismo y de la industria editorial, nuevas formas de publicación y circulación. En ese sentido, la producción literaria fue un espacio dinámico de construcción de sentidos e identidades antes que un depósito estático de referencias y novedades. La literatura decimonónica no solo se hizo eco de descubrimientos científicos y adelantos tecnológicos, sino que plasmó la forma en que cambió la percepción y comprensión del mundo. Gillian Beer (2009) ha mostrado con su estudio sobre Darwin y sus contemporáneos cómo al cambiar los patrones por los cuales se aprehende la experiencia, cambian los patrones narrativos con los que se da cuenta de ella y, al mismo tiempo, la forma en que científicos y escritores usan los mismos recursos en sus escritos. Mientras August Comte desarrollaba su "Cours de Philosophie positive" entre 1839 y 1842, en las letras galas estaba en pleno auge el realismo. La incorporación posterior de los principios positivistas a la literatura dio origen al naturalismo, así definido por Zola: "el naturalismo [...] consiste simplemente en la aplicación del método experimental al estudio de la naturaleza y el hombre" (García, 1993, p. 439).

La ciencia también aparecía en el prefacio a la primera edición de La Comedia Humana de Balzac en 1842, con referencias a la polémica entre los naturalistas Cuvier y Saint-Hilaire y la expresión de la necesidad de asimilar el método del escritor al del científico. Este cambio en la forma de concebir la producción literaria se complementó con la aparición de nuevos géneros y personajes. Así, como a la luz de estos cambios el siglo XIX vio el nacimiento del detective y el género policial de la mano de Poe, también surgieron el científico, el inventor y la novela científica (scientific romance) en la que también Poe tuvo algo que ver y que, con el tiempo, evolucionaría en la ciencia ficción. Lo científico produjo una renovación o actualización de lo fantástico: igual tema, distinto medio; lo que antes se alcanzaba mediante la fantasía, ahora se alcanza a través de la ciencia. Aunque no trata explícitamente sobre el viaje temporal, en "Three Sundays in a Week" (1850, originalmente publi- 
cado en 1841 como “A Succession of Sundays") Poe adopta una perspectiva racional para obtener los tres domingos en una misma semana aludidos en el título a partir de la conjunción de tres viajeros que, desde distintas zonas horarias circunnavegan la Tierra en distintas direcciones: la misma artimaña con que Phileas Fogg resuelve su viaje alrededor del mundo en ochenta días, en el libro de Verne de 1873. El cuento fue traducido y publicado en El Museo Universal de Madrid en febrero de 1857, constituyendo la primera traducción y publicación de Poe al español. La industria editorial española del siglo XIX puso en circulación muchas traducciones de este nuevo tipo de narraciones y de tratados de divulgación científica. Es que, como sostiene Laura Otis (2002), no hubo en el siglo XIX una brecha entre ciencia y literatura $-\mathrm{O}$, mejor, entre el discurso científico y el literario-, la cual se efectivizaría recién a partir de la conferencia que C. P. Snow brindó en mayo de 1959 y que sería publicada con el título The Two Cultures and the Scientific Revolution. De hecho, tanto en España como en el resto de Europa se utilizaban recursos literarios y filosóficos para sostener argumentaciones científicas o como medio de divulgación. Es el caso del Poema físico astronómico de Gabriel Siscar (1828) a quien podemos sumar, más cerca del siglo XX, a autores como Melchor de Palau, José Echegaray o Santiago Ramón y Cajal, que destacaron tanto en la literatura como en la ingeniería y la ciencia. Entre los autores más traducidos en España estaban Jules Verne, Emile Zola y Camille Flammarion. La tendencia se acrecentó cerca del cambio de siglo con la aparición de revistas como Germinal o Madrid Cómico que serializaron novelas y publicaron cuentos. El crecimiento de la industria editorial y de la prensa fue acompañado por una suerte de proto-industria cultural: dioramas, autómatas, fantasmagorías y, más tarde, el cine. No está de más recordar a Segundo de Chomón, un (casi) contemporáneo español de Georges Méliès y Émile Cohl, pionero de la técnica de animación stop motion (por ejemplo, El hotel eléctrico, de 1908).

Pero no fueron la científica y la industrial las únicas revoluciones decimonónicas. En el caso puntual de España, de la invasión francesa y los levantamientos populares de 1808 a la restauración borbónica en 1875 y el posterior "desastre" de 1898, el siglo se desarrolló en un crescendo de disputas sociales y políticas en que se enmarcó el conflictivo proceso de construcción de la idea nacional. El historiador Pérez Garzón (1999) sostiene que "España como realidad política, social y económica nace con el movimiento juntero de 1808 y tiene su partida de nacimiento en las Cortes de Cádiz" (p. 57). Sin embargo, el proceso que se inicia entonces no llega a desarrollar una identidad nacional entre la población española: “[...] la articulación del Estado por la revolución española, desde sus propios orígenes, cobijó alternativas nacionales diferenciadas sin que lo español tuviese significados unívocos" (Pérez Garzón, 1999, p. 58). Y como señala M. Mann, "la nación no fue una comunidad total. El localismo sobrevivió, como lo hicieron las barreras regionales, religiosas, lingüísticas y de clase dentro de las fronteras nacionales" (Pérez Garzón, 1999, p. 61). 
Las ideas liberales importadas de Europa -en particular, de Francia- convivían con el arcaico mito romántico en una dinámica de permanente contraste entre lo moderno/occidental y lo antiguo/oriental. Propuesta por el historiador catalán Borja de Riquer (1994) en "La débil nacionalización española del siglo XIX" y popularizada por José Álvarez Junco (2001) en Mater Dolorosa. La idea de España en el siglo XIX, la tesis de la "débil nacionalización" carga al Estado la falta de capacidad para cimentar y construir una identidad nacional unívoca entre la población española. Esta tesis ha sido posteriormente revisada (v. Archilés \& Martí, 1999, 2005; Archiles, 2006; Botrel, 2007; Andreu Miralles, 2016) a partir de la incorporación de conceptos de autores como Benedict Anderson (1983) y Homi Bhabha (1990), responsables de obras como Comunidades Imaginadas o Nación y narración, respectivamente, las cuales se alejan de concepciones esencialistas de la nación, enfatizan su carácter histórico y construido, a la vez que destacan el papel que la cultura -en particular la novela (v. Culler, 2003)- tiene como espacio de construcción de imaginarios. A ellos podemos agregar aportes como el de Gregory Jusdanis (2001), para quien la "extraordinaria autoridad" de intelectuales (poetas, escritores, filósofos) en los procesos de construcción de identidades nacionales, iguala o supera en fuerza el poder de las máquinas, la eficiencia de las fábricas o la violencia de las armas. Este grupo social vehiculiza, junto con las elites, el "efecto de comparación" al recorrer otras tierras y verificar la diferencia de poder, cultura o modernización respecto del propio terruño (pp. 96-101). Para historiadores como Xavier Andreu Miralles, Manuel Martí y Ferrán Archilés, la literatura, entendida como una forma de relación social y política

se reveló como un espacio privilegiado para estudiar los discursos, entendidos como formas de concebir y de representar la realidad con efectos de poder y de creación de significados. Más que como un reflejo del mundo en el que habitaba, empezó a ser percibida como partícipe activa en su conformación y transformación. Las consecuencias políticas de la actividad literaria y de quienes la practicaban se hicieron así evidentes. (Andreu Miralles, 2016, p. 15)

Las tensiones en torno a la identidad nacional atraviesan la producción literaria decimonónica articuladas en muchos casos a partir del efecto de comparación postulado por Jusdanis, en el cual la introducción del elemento científico o tecnológico es fundamental para contrastar avances foráneos y anacronismos locales. Allí está el paradigmático caso de Pérez Galdós. Menéndez y Pelayo (1882) veía en él a un anticlerical, razón por la cual lo incluyó (junto con otros) entre los "heterodoxos españoles": "Los católicos vienen a representar [...] sobre todo en Doña perfecta, el papel de los traidores de melodrama, persiguiendo y atribulando siempre a esos ingenieros sabios, héroes predilectos del autor" (p. 812). En la novela en cuestión el "ingeniero sabio" es Pepe, "hombre de elevadas ideas y de inmenso amor a la ciencia [...] génio del siglo" (Pérez Galdós, 1878, p. 30), que contrasta con su padre, el 
abogado Don Juan, en relación a Orbajosa, el pueblo donde se desarrollará el relato. Visto como un "horrible" y "salvaje poblacho" por otros personajes, Don Juan se desvive en elogios:

¡Qué patriarcales costumbres! ¡Qué nobleza en aquella sencillez! ¡Qué rústica paz virgiliana! Si en vez de ser matemático fueras latinista... iQué admirable lugar para dedicarse a la contemplación de nuestra propia alma y prepararse a las buenas obras! Allí todo es bondad, honradez; allí no se conocen la mentira y la farsa como en nuestras grandes ciudades; allí renacen las santas inclinaciones que el bullicio de la moderna vida ahoga; allí despierta la dormida fé. (Pérez Galdós, 1878, pp. 32-33)

Una novela posterior del autor, Marianela, es paradigmática en lo relativo a la construcción del personaje del científico y la definición del lugar de la ciencia en España. Su protagonista, el oftalmólogo y cirujano Teodoro Golfín, viajó

a América donde trabajó juntamente con otros afamados médicos europeos [...] hizo un viaje a España, tornó al Nuevo Mundo, vino más tarde para regresar al poco tiempo. En cada una de estas excursiones daba la vuelta a Europa para apropiarse los progresos de la ciencia oftálmica que cultivaba. (Pérez Galdós, 1888, p. 87)

Aquí se aprecia la tensión entre España y el extranjero: es en otros países donde están los progresos de la ciencia. Esta tensión es enfatizada por los verbos que describen la relación de Golfín con dichos progresos: cultivar, que remite al entorno y la actividad rural, y apropiarse, hacer propio algo que es ajeno, que pertenece a otro. El imaginario desarrollado por Pérez Galdós se condice con la visión romántica y exótica que Europa tenía de España: “[...] el reverso de la modernidad. [...]. [Un pueblo incapaz] de acceder al mundo moderno. [...] Un país situado supuestamente en los márgenes de Europa y de la modernidad" (Andreu Miralles, 2016, p. 12).

Hijo de una pareja de actores, Enrique Gaspar (Madrid, 1842 - Oloron, 1902) fue un dramaturgo precoz (escribió su primera zarzuela a los trece años), actividad que no abandonó pero pasó a segundo plano al iniciar en 1869 una carrera diplomática que lo alejaría físicamente de España. Residió en Grecia, China y Francia, donde además del teatro cultivó la escritura de crónicas de viaje y novelas, entre ellas El anacronópete, de 1887 . Fue rescatada del olvido a mediados de la década de los noventa a través de su inclusión en la antología De la luna a Mecanópolis. Antología de la ciencia ficción española (1832-1913), de Nil Santiáñez-Tió. Ya en el siglo XXI una exhibición de ciencia ficción realizada en la Biblioteca Británica en 2011 y algunos artículos de la prensa inglesa le dieron visibilidad y propiciaron su traducción y publicación en 2012 con el título The Time Ship. A Chrononautical Journey. El "gancho" fue el haberse anticipado ocho años a la publicación de The Time Machine de H. G. Wells, convencionalmente considerada la primera novela en presentar una máquina que permite viajar en el tiempo. El dato, aunque cierto, no deja de ser anecdótico. La proliferación de relatos científicos (y de autores "ama- 
teurs" que el tiempo ha olvidado) apañada por la profusión de publicaciones (revistas, diarios, etc.) permite considerar la posibilidad de algún relato previo que espera ser re-descubierto. Vale la pena recordar lo acontecido al propio Wells tras la publicación en 1901 de The First Men in the Moon, cuando un ignoto escritor irlandés, Robert Cromie, lo acusó de haber plagiado de su relato A Plunge into Space (1890) por la utilización de la "anti-gravedad" como medio para llegar al satélite, aunque en realidad, y sin que Cromie o Wells lo supieran, Percy Greg se les había adelantado con Across the Zodiac: The Story of a Wrecked Record (1880) y, más temprano aún, Chrysostom Trueman con The History of a Voyage to the Moon (1864).

El viaje a la Luna fue hasta 1969 un (sub)género en sí mismo, cuyos antecedentes pueden rastrearse hasta Luciano de Samosata y su Historia verdadera en los primeros siglos de la era cristiana y sobre el fin del XIX y principios del XX, en Verne (De la Terre à la Lune Trajet direct en 97 heures, 1865 y Autour de la Lune, 1870) y la obra ya mencionada de Wells, pasando por Dante, Cyrano de Bergerac o Kepler, entre otros. En España está la novela de Joaquín del Castillo Mayone Viage somniaéreo a la Luna (1832), en la cual el viaje en sí no llega a concretarse, no "físicamente" al menos: el personaje se duerme en un globo y sueña la llegada a la luna. ${ }^{1}$ A esta pueden sumarse Somnium (1532), de Juan Maldonado; Viaje fantástico (1724), de Torres Villarroel; Sizigias y cuadraturas lunares (1775), de Manuel Antonio de Rivas; Parábola sobre la religión y la política entre los selenitas (1787), de José Marchena; Viage de un filósofo a Selenópolis, de Don Antonio Marqués y Espejo (1804); Lunigrafia ó noticias curiosas sobre las producciones, lengua, religión, leyes, usos y costumbres de los lunícolas, de Miguel Estorch y Siqués (1857); Selenia, de Aureliano Colmenares (1873), o De Madrid a la Luna, de Carlos Luis de Cuenca (1886). También hay un par de casos pioneros de viajes a otros planetas del sistema solar: Una temporada en el más bello de los planetas, de Tirso Aguimana de Veca (Agustín María Acevedo Rodríguez), publicada por entregas en 1870, -novela que relata el viaje del científico alemán Leynoff y el joven español Mendoza a Saturno usando "corrientes de comunicación" interplanetariasy, en 1871, Un viaje al planeta Jupiter: aventuras del Marqués de Belmonte, de Antonio de San Martín, planeta al que volvería Enrique Bendito y Trujillo en Un viaje a Júpiter, de 1899. Igualmente se registran viajes a planetas imaginarios, como en Castillo de naipes en el planeta Juno (1891), de Francisco Ramos de Pablo, y en Astolfo, Viages an Un Mundo Desconocido, su Historica, Leyes y Costumbres (1838), de Don Federico de Madrazo.

Junto a los populares viajes a otros mundos aparecieron los viajes en el tiempo. En la literatura europea existen casos como Memoirs of the Twentieth Century (1733), de Samuel Madden; Anno 7063 (1781), de Johan Herman Wessel; "Rip Van

\footnotetext{
${ }^{1}$ Curiosamente, tres años después, desde el otro lado del Atlántico Poe publicaría el cuento "The Unparalleled Adventure of One Hans Pfaall”, donde sí se llega a la Luna en un globo.
} 
Winkle" (1819), de Washington Irving; "A Christmas Carol” (1843), de Charles Dickens; o "The Clock That Went Backward" (1881), de Edward Page Mitchell, y El anacronópete, de Gaspar (1887). La particularidad de esta novela excede el hecho anecdótico de anticiparse a Wells ${ }^{2}$ presentando la primera "máquina" del tiempo, es decir "la mecánica de un aparato diseñado por el hombre sustituye, en la fabulación literaria, a los habituales medios de viaje temporal (el sueño, el encantamiento, la hipnosis, la hibernación)” (Santiáñez-Tió, 1995, p. 16). Además del valor en relación al desarrollo del género fantástico -o una proto-ciencia ficción- es operativo incorporar la perspectiva historiográfica que describíamos arriba y considerar la novela como espacio de discursos en disputa en torno a la configuración de la identidad nacional, disputa en la que el elemento fantástico/científico está imbricado. La novela de Gaspar extiende los límites del relato fantástico: ya no puede pensárselo, de acuerdo con Todorov (1975), como ese momento de incertidumbre entre la aceptación de lo sobrenatural o su explicación (p. 25) ya que lo sobrenatural es presentado como natural. En la novela esto se desprende de la descripción "científica" de la naturaleza del tiempo que elabora el protagonista en el segundo capítulo (v. Gaspar, 1887, pp. 17-21). En todo caso, podría pensarse que la introducción del razonamiento científico en los relatos habría desplazado el eje de lo fantástico a lo posible. Cabe recordar la crítica de Verne al viaje lunar de Wells por ser realizado a través de medios ficticios. A Verne le interesa lo técnica y mecánicamente posible, mientras que Wells se vale referencialmente de esos elementos para abordar temas sociales en una dinámica condensada en el título de uno de los Cuentos Ilustrados publicados en 1895 por Nilo María Fabra: "lo presente juzgado por lo porvenir en el siglo XX". El viaje a otros tiempos o planetas impone una distancia que permite poner en perspectiva problemáticas sociales contemporáneas.

El concepto de "límite" o "frontera", así como la tensión resultante entre los elementos separados, es fundamental para pensar el texto de Gaspar que, en sí, es una novelización o adaptación narrativa de una obra teatral, según consta en la portada del manuscrito de la obra, fechado en 1884: "El Anacronópete: zarzuela: viaje atrás verificado en el tiempo desde el último tercio del siglo XIX hasta el caos y dividido en tres jornadas y trece cuadros" (Gaspar, 1884, p. 1). Decíamos antes que El anacronópete extiende la frontera del relato fantástico mediante la incorporación de la descripción científica de la naturaleza del tiempo, que desplaza la tensión entre lo natural y lo sobrenatural a lo técnica o científicamente posible-imposible. El primer capítulo de la novela permite apreciar la popularidad en España del "famoso Julio Verne", cuyas "maravillosas hipótesis" serán consideradas "juguetes de niño ante la magnitud del invento real del modesto zaragozano vecino de la Corte de las Españas" (Gaspar, 1887, p. 10). En una rápida sucesión se desacreditan algunos de

\footnotetext{
${ }^{2}$ En ese sentido, otro español, José Fernández Bremón se le habría anticipado también con su relato "Un crimen científico" de 1879 a The island of Doctor Moreau de 1896.
} 
los argumentos de las conocidas novelas del autor francés: "bajar al centro de la tierra es cuestión de abrir un orificio por donde verificar el descenso" o "ir al polo esperando el deshielo es obra de pura paciencia; copia servil aunque sabia de esas personas que, para hacer compras en un almacén, aguardan a que la tienda esté en liquidación" (Gaspar, 1887, p. 10). Es interesante el contraste que el autor construye entre las "maravillosas hipótesis" de Verne y el "invento real" de D. Sindulfo García, enfatizado en ese mismo párrafo al comparar el (maravilloso) Nautilus de Verne con el (real) Ictíneo de Narcís Monturiol, el cual, botado en 1864, fue el primer submarino tripulado con motor de propulsión que no consumía el aire de la cabina. El elemento científico es definido a partir del eje maravilloso-real atravesado por lo nacional, colocando lo maravilloso en Francia y lo real en España. Sin embargo, la acción se desarrolla en París en ocasión de la Exposición Universal de 1878. Francia fue durante el siglo XIX depositaria de la modernidad y el progreso, el modelo al que aspiraban liberales e intelectuales españoles, y el que operaba el "efecto de comparación" que postula Jusdanis. Pero, además, señala Pérez Garzón (1999), jugó un papel crucial en la difusión de los estereotipos sobre el arte, la cultura y la música que definían la nacionalidad española (p. 81), lo cual cobrará importancia en relación al final de la novela. En el relato, París, "foco de la animación, centro del movimiento, núcleo del bullicio" y "cerebro del mundo" (Gaspar, 1887, pp. 7, 12), encarna un valor de modernidad y progreso al ser la sede de la Exposición Universal. Sin embargo, al mismo tiempo propone un distanciamiento irónico de ese valor a partir de la comparación con las "maravillas" de Verne y la introducción de prodigios tecnológicos "reales" (la máquina a vapor, la locomotora, el globo aerostático) que serán opacados por el invento del protagonista, especialmente por el hecho de ser "hasta entonces oscuro y español por añadidura" (Gaspar, 1887, p. 9).

Esta distancia irónica se verifica en la novela a través de tensiones en la caracterización del protagonista. Inicialmente es descripto como "doctor en ciencias exactas, físicas y naturales", "coloso científico" y "héroe con la modestia propia del talento impresa en el semblante" (Gaspar, 1887, pp. 11, 12, 16) lo que parece confirmarse a partir de la explicación de la naturaleza del tiempo. Se trata de una extensa disertación que ocupa todo un capítulo mezclando nociones científicas, en particular de Camile Flammarion, con el que Gaspar tuvo amistad y a quien se hace referencia más adelante en la novela (Gaspar, 1887, p. 86) y pseudocientíficas inventadas por el autor. A pesar del encomio inicial, la descripción final de García es bien distinta:

Todo en él era vulgar. Su nombre más que de sabio parecía de barba de sainete. Su apellido no estaba ligado por ninguna partícula a esas hojas patronímicas que, como Paredes, o Córdoba, prestan frondosidad a los árboles genealógicos. Llevaba sus cincuenta años, no con el soberbio orgullo del titán aportando la piedra para escalar el cielo, sino con la resignación del mozo que transporta un baúl. Pequeñito, con sus cabellos lisos y en correcta formación, el traje muy cepilladito y como colgado de su armazón de 
huesos. Tenía una de esas caras que parecen hechas bajo la influencia del nombre del que las ha de ostentar. En suma, era digno de llamarse D. Sindulfo García y merecedor del apodo de Pichichi que su criada le había puesto por sambenito. (Gaspar, 1887, p. 17)

En forma similar, se revela que "erudición a un lado, el invento de don Sindulfo no era debido, como lo parecía, a su amor por la ciencia; sino a un interés doméstico, mejor diré, a una mira puramente personal" (Gaspar, 1887, p. 34). Inicialmente Sindulfo declara lo siguiente: "mi propósito nadie lo ignora, es retroceder en el tiempo, no para detener el continuo movimiento de avance de la vida, sino para deshacer su obra y acercarnos más a Dios encaminándonos a los orígenes del planeta que habitamos" (p. 17), aunque el interés "doméstico" y "personal” que persigue realmente es doblegar la voluntad de su sobrina, Clara, a quien pretende como esposa:

¿Por qué se habrán liberalizado tanto las leyes? Dichosos tiempos aquellos en que un tutor tenía derecho de imponerse a su pupila. ¿Quién pudiera transportarse a aquella época, mal llamada de oscurantismo, en que el respeto y la obediencia a los superiores constituían la base de la sociedad? ¡Si yo pudiese retrogradar en los siglos! (Gaspar, 1887, pp. 43-44)

A lo largo de la novela presenciaremos, más allá del humor y las ironías, cómo Sindulfo asesina un par de veces al pretendiente de su sobrina -que "revive" por efecto del viaje- para finalmente lanzar en un rapto de locura el anacronópete a la destrucción: "la muerte nos espera a todos en el caos" (Gaspar, 1887, p. 216). Esta es la clave de la novela, el punto donde convergen - a partir de la tensión irónica que rodea al protagonista- las líneas de lo científico y la construcción de una identidad nacional, que se traduce en una suerte de esencialismo pesimista y que está presente desde el mismo título: “Aná que significa hacia atrás, cronos el tiempo y petes el que vuela, justificando de este modo su misión de volar hacia atrás en el tiempo" (Gaspar, 1887, p. 27). Sindulfo García no busca juzgar lo presente por lo porvenir como harán tantos textos de viajes temporales (la novela de Wells, por ejemplo), sino que intentará "llegar al descubrimiento de la verdad retrogradando, en un siglo que busca sus ideales en el mañana y que acepta el adelante como fórmula del progreso" (Gaspar, 1887, p. 14). La idea es resaltada por el título del primer capítulo, "En el que se prueba que ADELANTE no es la divisa del progreso" (Gaspar, 1887 , p. 7), y presenta una marcada distancia respecto a contemporáneos que propugnaban abrazar formas de modernidad y progreso. A modo de ejemplo, en $\mathrm{Ver}$ dades poeticas (1881) Melchor de Palau conmina a una musa suicida: "en moldes nuevos / vaciar debes tus obras inmortales [...] con hilos del telégrafo reemplaza / las ya insonoras cuerdas de la lira". Los que serían, en comparación, "moldes viejos" aparecen como "ídolos, por tierra derribados" o "juegos infantiles" que deben ser conservados en "clásico museo / pero no en el altar". El prólogo de Rodriguez Carracido a la edición de 1892 era tajante: “sepúltense en las capas formadas por el 
sedimento histórico los fósiles de la poética clásica [...] minucias de sintaxis, detalles prosódicos [y otros] trabajos rastreros". Las ironías respecto a los adelantos tecnológicos "reales" enumerados en el primer capítulo se completan con la constatación de la ignorancia del presente respecto del pasado en el capítulo XII, donde tras arribar a China en el año 220 los protagonistas constatan los errores de la ciencia decimonónica.

- Tu ignorancia me asusta -le contestó el calado-. ¿No sabes que ese descubrimiento tuvo lugar en el año sesenta y uno del reinado de Hoang-ti, época en que dan principio para los letrados los tiempos históricos de la China y el ciclo de sesenta años divididos éstos en 365 días y 6 horas, base de nuestro cómputo?

$[\ldots]$

- Pero esa invención - añadió Benjamín oponiéndose aún a la evidencia- como la de los pozos artesianos, la porcelana, los puentes colgantes, los naipes y el papel moneda, no datan en China, según nuestros historiógrafos, sino de los siglos octavo al trece, y estamos a principios del tercero. Pues si bien es cierto que el sabio sinólogo Estanislao Julien comunicó en 1847 a la academia de ciencias de París la fecha de ciertos descubrimientos de los chinos, las épocas que cita parecen tan fabulosas que el orgullo europeo se resiste a aceptarlas. (Gaspar, 1887, pp. 128-129)

El narrador critica "el orgullo de un hijo del siglo XIX que, engreído con las conquistas de su época, cree poder burlarse impunemente de sus antecesores, a quienes, después de todo, debe la base de unos conocimientos que él no ha hecho las más veces sino perfeccionar" (Gaspar, 1887, p. 127).

El viaje al pasado impone una interrogación sobre el origen, sobre la identidad nacional, en un contrapunto entre el carácter esencial (Sindulfo García) y el histórico/construido (Benjamín) de la misma:

- ¿No cree usted que dando un curso de moral a la Cava y a don Rodrigo, o haciendo ver al conde don Julián las consecuencias de su traición, lograríamos torcer el rumbo de los acontecimientos e impedir que hubiera tenido lugar la dominación árabe en España?

- De ningún modo. Nosotros podemos asistir como testigos presenciales a los hechos consumados en los siglos precedentes; pero nunca destruir su existencia. Más claro; nosotros desenvolvemos el tiempo, pero no lo sabemos anular. Si el hoy es una consecuencia del ayer y nosotros somos ejemplares vivos del presente, no podemos, sin suprimirnos, aniquilar una causa de que somos efectos reales. Un símil le patentizará a usted mi teoría. Figúrese usted que usted y yo somos una tortilla hecha con huevos puestos en el siglo VIII. No existiendo los árabes, que son las gallinas, ¿existiríamos nosotros?

[...]

- ¿Y por qué no? Aun admitiendo la hipótesis de que ambos seamos descendientes del moro, el evitar que éste y los suyos penetren en España no impide nuestra existencia. Yo no destruyo las gallinas; lo que hago es obligarlas a que sigan poniendo en África. Luego la tortilla puede subsistir sin otra diferencia que tener el Atlas por hornillo en lugar del Guadalete. (Gaspar, 1887, p. 74) 
Detrás de las ironías y humoradas teatrales, la resolución del viaje es negativa; de acuerdo al estereotipo romántico, el protagonista termina siendo un ser primitivo, incapaz de controlar sus pasiones, en el que la ciencia se asocia a la locura, el crimen y la muerte. El viaje termina siendo un sueño del narrador que se quedó dormido durante la representación de una obra teatral de Verne, en la que los aplausos finales del público son el estrépito del caos primigenio al que se lanza su malhadado científico. Cabe preguntarse a qué se refiere el narrador al afirmar lo siguiente: "cuando por el camino contó el sueño a su familia, todos rieron grandemente; lo que dudo mucho que haya acontecido a mis lectores con este relato" (Gaspar, 1887, p. 217); ¿se refiere a la decepción que implica para los lectores el carácter onírico del viaje o tiene que ver con algo del orden de lo identitario, la decepción de reconocerse españoles? El final del texto parecería apuntar a lo segundo:

Hay que reconocer que mi obra tiene por lo menos un mérito: el de que un hijo de las Españas se haya atrevido a tratar de deshacer el tiempo, cuando por el contrario es sabido que hacer tiempo constituye la casi exclusiva ocupación de los españoles. (Gaspar, 1887, p. 218)

En conclusión, complejizar la lectura de esta novela a partir de una articulación multidisciplinar que incorpore tendencias actuales de la historiografía y la sociología permite extender el interés por el texto más allá de su pertenencia genérica. Más allá del dudoso mérito de haberle "ganado" a Wells, su atractivo está en la forma en que teje los hilos de la ciencia y la literatura en el entramado de la construcción de una identidad nacional que, lejos de la fantasía especulativa, está fuertemente anclada en una caótica coyuntura contemporánea cuyos efectos aún perviven:

La atmósfera no es más que una aglomeración de átomos imperceptibles, del mismo modo que una playa no es otra cosa que la reunión de millones de granos de arena. $\mathrm{O}$ si la queremos más perceptible, la atmósfera es una vastísima plaza pública llena de gente en un día de revolución. (Gaspar, 1887, p. 30)

Los contrastes entre Francia y España, entre el coloso de la ciencia devenido loco asesino, entre el científico y el humanista, entre la novela devenida sueño, aparecen, en la visión crítica (y pesimista) de Gaspar, inherentes a la identidad, al ser español. Difícilmente sea gratuito que la primera parada del viaje del anacronópete sea la batalla de Tetuán:

La jornada ha sido completa. Tetuán no tardará en abrir sus puertas al vencedor, y el emperador de Marruecos debe ya empezar a arrepentirse de haber excitado el justo enojo de la nación española. El entusiasmo a bordo no reconocía límites. Todos suplicaban a don Sindulfo que les permitiese bajar para dar un abrazo a aquellos héroes. (Gaspar, 1887 , p. 89) 
A lo que el científico se niega, escatimando al lector el final de la historia, con los héroes de guerra que quedaron, en los suburbios de la capital, a la espera de una entrada triunfal que nunca aconteció, mientras el provisorio campamento militar devenía asentamiento permanente -hoy Tetuán de las Victorias-. Expectativa frustrada, igual que la del lector de la novela que termina siendo un sueño. 


\section{REFERENCIAS BIBLIOGRÁFICAS}

Álvarez Junco, J. (2001). Mater Dolorosa. La idea de España en el siglo XIX. Madrid: Taurus.

Anderson, B. (1983). Imagined Communities: Reflections on the Origin and Spread of Nationalism. Londres \& Nueva York: Verso.

Andreu Miralles, X. (2016). El descubrimiento de España. Mito romántico e identidad nacional. Barcelona: Taurus.

Archilés, F. (2006). "Hacer región es hacer patria". La región en el imaginario de la nación española de la Restauración. Ayer, 64, 121-147.

Archilés, F. \& Martí, M. (1999). La construcción de la Nación española durante el siglo XIX: logros y límites de la asimilación en el caso valenciano. Ayer, 35, 171-190.

- (2005). Una nació fracassada? La construcció de la identitat nacional espanyola al llarg del segle XIX. Recerques, 51, 141-163.

Beer, G. (2009). Darwin's Plots. Evolutionary Narrative in Darwin, George Eliot and NineteenthCentury Fiction ( $3^{\mathrm{a}}$ ed.). Cambridge: Cambridge University Press.

Bhabha, H. (ed.) (1990). Nation and Narration. Nueva York: Routledge.

Botrel, J. (2007). Cosmopolitismo y mediación cultural en la España del siglo XIX. Península: Revista de Estudios Ibéricos, 4, 35-44.

Culler, J. (2003). Anderson and the Novel. En J. Culler \& P. Cheah (eds.), Grounds of Comparison. Around the work of Benedict Anderson (pp. 29-52). Nueva York: Routledge.

García, A. M. (1993). Antecedentes literarios y estéticos del "naturalismo galdosiano": La desheredada. En J. Bombín Quintana (coord.), Actas del Cuarto Congreso Internacional de estudios galdosianos (1990) (pp. 439-456). Las Palmas de Gran Canaria: Ediciones del Cabildo Insular de Gran Canaria.

Gaspar, E. (1884). El Anacronópete: zarzuela: viaje atrás verificado en el tiempo desde el último tercio del siglo XIX hasta el caos y dividido en tres jornadas y trece cuadros. [Manuscrito digitalizado]. Consultado el 11 de septiembre de 2017 en http://bdh-rd.bne.es/viewer.vm?id= 0000014484\&page $=1$

- (1887). El Anacronópete. Viaje a China. Metempsicosis. Barcelona: Daniel Cortezo y Ca

Jusdanis, G. (2001). The Necessary Nation. Princeton: Princeton University Press.

Menéndez y Pelayo, M. (1882). Historia de los heterodoxos españoles, III. Madrid: Libreria Católica de San José.

Otis, L. (2002). Literature and Science in the Nineteenth Century. An Anthology. Oxford: Oxford University Press.

Pérez Galdós, B. (1878). Doña Perfecta. Madrid: Imprenta de la Guirnalda.

- (1888). Marianela. Madrid: Imprenta de la Guirnalda.

Pérez Garzón, J. (1999). El nacionalismo español en sus orígenes: factores de configuración. Ayer, $35,53-86$.

Riquer, B. de (1994). La débil nacionalización española del siglo XIX. Historia Social, 20, 97-114.

Santiáñez-Tió, N. (1995). De la luna a mecanópolis. Antología de la ciencia ficción española (1832-1913). Barcelona: Quaderns Crema.

Todorov, T. (1975). The Fantastic: A Structural Approach to a Literary Genre. Ithaca: Cornell University Press. 